\title{
PENETRATION PROBLEM FOR INFRASTRUCTE STABILITY IN CONDITIONS OF OFFSHORE FIELDS DEVELOPMENT
}

\author{
Nikita V. Dubinya ${ }^{1,2}$, Sergey A. Tikhotskiy ${ }^{1,2}$, Maria A. Krasnova ${ }^{1,2}$ and Victor A. \\ Nachev ${ }^{1,3}$ \\ ${ }^{1}$ Moscow Institute of Physics and Technology \\ 9 Institutskiy p., Dolgoprudny, Moscow Reg. 141701 \\ Dubinya.NV@gmail.com, Tikhotskii.SA@mipt.ru, MKrasnova@ifz.ru, Nachev@phystech.edu, \\ https://mipt.ru/english/ \\ ${ }^{2}$ Schmidt Institute of Physics of the Earth RAS \\ Bolshaya Gruzinskaya str., 10-1 Moscow 123242 \\ http://www.ifz.ru/en/ \\ ${ }^{3}$ Sadovsky Institute of Geosphere Dynamics of Russian Academy of Sciences \\ Leninskiy p., 38-1 Moscow 119334 \\ http://idg.chph.ras.ru/en/
}

Key words: Offshore Reservoir Development, Infrastructure, Seafloor Sediments.

\begin{abstract}
The paper is generally devoted to the problem of offshore oil and gas fields' development. The main focus of the study is mechanical behavior of seafloor sediments and stability of infrastructure objects' supporting constructions. We study the problem of estimating the effective mechanic properties of seafloor sediments. To solve the problem, we propose the usage of gravity corer of bottom sediments. These corers make it possible to study dynamic elastic properties at the ship laboratory conditions. We study the sampling process itself as a tool to estimate the rheological properties of seafloor sediments. In the current study, we propose a specific analysis of the samples and sampling process. The sampling corer is equipped with tools providing an opportunity to measure its acceleration at each moment during the sampling process. This acceleration depends on controllable sampling process conditions and mechanical properties of seafloor sediments being sampled. A corresponding contact problem is considered using the finite-element method. It is shown that there is an opportunity to evaluate some (but not all) parameters for visco-elasto-plastic rheology of the sediments from a known acceleration of the sampling tube. The obtained results make it possible to improve the quality of model of mechanical properties of the seafloor sediments. This improvement provides the corresponding increase in mechanical modeling of infrastructure stability and decreases the risks accompanying offshore field development.
\end{abstract}




\section{INTRODUCTION}

The Russian continental shelf is currently being actively explored, as the Russian part of the Arctic contains a quarter of Russia's oil and gas condensate reserves and about $70 \%$ of its gas reserves.

Today's primary type of drilling rig for field exploration and production of hydrocarbons used on the offshore shelf is a self-lifting drilling platform. Its base is a hollow and floating metal pontoon, surrounded by supports resting on the ground. The length of the supports is adjustable, and they can sink into the ground, if it is strong enough for this, rely on the "soles" of a large area or attach to special fixing bottom structures. Since the platform releases from the factory already prepared, engineers need to know what method of fixing the supports they will use at the drilling site. That is often very difficult to understand, especially on the Arctic sea shelf, where there is less drilling experience than on the mainland, and marine soils often differ dramatically in their strength and inner structure.

The second problem that arises during shelf development is the issue of evacuation. When the platform is exposed to strong external influences: strong waves, the effects of earthquakes and contact with hummocks, there is risk of its destruction [1]. However, for the supports to be quickly removed in case of danger, it is necessary to take into account the mechanical properties of the bottom sediments with sufficient accuracy. That is not an easy task: if the bottom sediments are more viscous than the design of the self-lifting rig is designed for, then evacuation cannot be carried out, and the drilling platform can be destroyed. In Arctic conditions, knowing

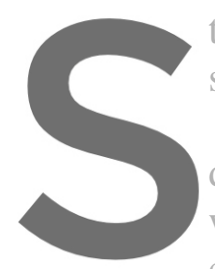
the seafloor's properties shelf.

To find out the soil drilling in the area of futing what they need to do
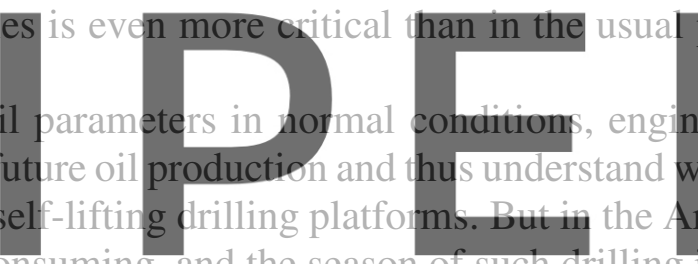

expensive and time-consuming, and the season of such drilling is limited in time.

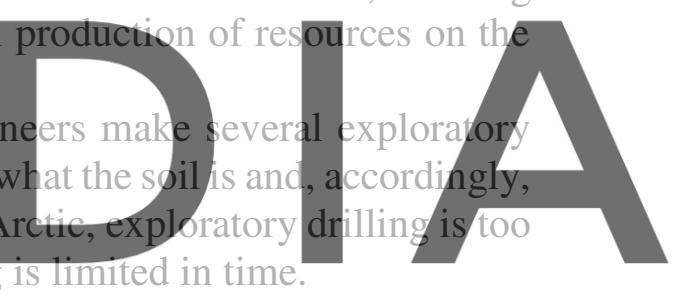

To obtain the maximum amount of data on the mechanical properties of the upper layers of

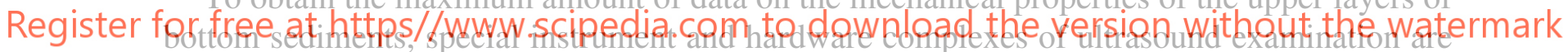

created. First, the soil sample is taken into the sea using gravity corers and then examined by uitrasound to understand how strong the local bottom sediments are and which support structures are best suited for this part of the shelf.

At the same time, seismic studies allow us to judge the velocities of elastic waves in media. Simultaneously, the upper layers of bottom sediments have complex visco-elasto-plastic rheology [2], the parameters of which are difficult to determine based on the results of interpretation of seismic survey data.

In this regard, the task of creating alternative methods for assessing the mechanical properties of the upper layers of bottom sediments is relevant, one of which is discussed in this paper. These corers make it possible to study dynamic elastic properties at the ship laboratory conditions: we introduce an algorithm to study dynamic elastic moduli of the samples using multilevel ultrasonic studies [3]. At the same time, we study the sampling process itself as a tool to estimate rheological properties of sea-floor sediments. In the current study we propose a specific analysis of the samples and sampling process. 


\section{THE PROBLEM}

To sample, the engineers use a gravity corer carried out from the vessel's side. The gravity corer can be represented as a hollow cylinder with an external diameter of $127 \mathrm{~mm}$, a wall thickness of $5 \mathrm{~mm}$, and a length of $3 \mathrm{~m}$. The corer's weight is $100 \mathrm{~kg}$. For better penetration into the ground, the corer is equipped with two additional loads of $80 \mathrm{~kg}$. Lifting and lowering the corer are carried out through a winch (the speed of unwinding the cable is $\sim 1-1.5 \mathrm{~m} / \mathrm{s}$ ), installed on the vessel's board. At the initial sampling stage, the gravity corer is lowered to the sea floor's surface and then released. The sea floor's typical depths at the studied objects are from 25 to $100 \mathrm{~m}$. Before entering the bottom soil, the winch stops, and the gravity corer is hung above the seafloor. When stopping, the distance from the bottom of the corer to the seafloor is units of meters. Further, under its weight, it accelerates, penetrates the ground $(\sim 1.5 \mathrm{~m} / \mathrm{s})$, and is filled with sediment.

The sampling depth depends on the technical means used and the sediments' composition. As a rule, when using a gravity corer with a length of $3 \mathrm{~m}$, the maximum core yield is between 1.5 and 2.5 meters (associated with the maximum depth of immersion), depending on the type of cut.

Before sampling, a plastic liner (diameter $100 \mathrm{~mm}$ ) is inserted into the steel pipe, into which the bottom sediments are taken. When the corer is raised, the core hole located at the bottom of the corer is closed, allowing the sediment to remain inside, while the sediment's primary deposit is preserved. After removing the gravity corer from the sea, the liner is removed with the core.

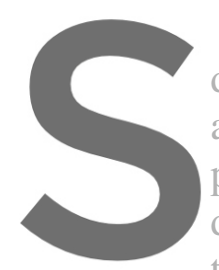

In realistic condition

during the process of falling to the ground and sinking into acceleration is influenced by the soil's rheological properties pronounced creep and plastic properties. The possibility of determining the class of rheological models of the soil based tube acceleration on time is considered. To solve this problem, numerical simulation is performed.

Register for free at https//www.scipedia.com to download the version without the watermark 3 NUMERICAL MODELING

To solve the problem of immersion of this tube in sediments with complex rheology, numerical modeling by the finite element method is actively used. Numerical simulations are performed using the finite element method with an implicit scheme. Numerical simulation of immersion of a gravity corer to a given depth in the ground with pre-known mechanical parameters for determining the sea soil's mechanical parameters during sampling (Young's modulus, Poisson's ratio, etc.) is carried out.

After a series of numerical experiments with known mechanical properties of marine sediments, we can determine the acceleration of the gravity corer into the soil and determine the dependence of the acceleration on the mechanical parameters of the seafloor sediments. Thus, it will be possible to solve the inverse problem of determining the soil's mechanical parameters based on the acceleration of the sampler.

In the described model, the water resistance was not taken into account at the current modeling stage, and the sampler falls freely. A sufficiently large soil area is modeled to compensate for boundary effects. The simulated area's linear size is an order of magnitude larger than the gravity corer's maximum linear dimension. 
At the first stage, a set of direct problems is solved. We determine the dynamics of immersion of the gravity corer in a visco-elasto-plastic medium with variable rheological parameters. The corer is considered as an elastic body that falls on a space with variable rheological properties. The gravity corer's mechanical parameters are the next: Young's modulus $E$ is $130 \mathrm{GPa}$, Poisson's ratio $\mu$ is 0.3 , density $\rho$ is $13000 \mathrm{~kg} / \mathrm{m}^{3}$ (Figure 1).

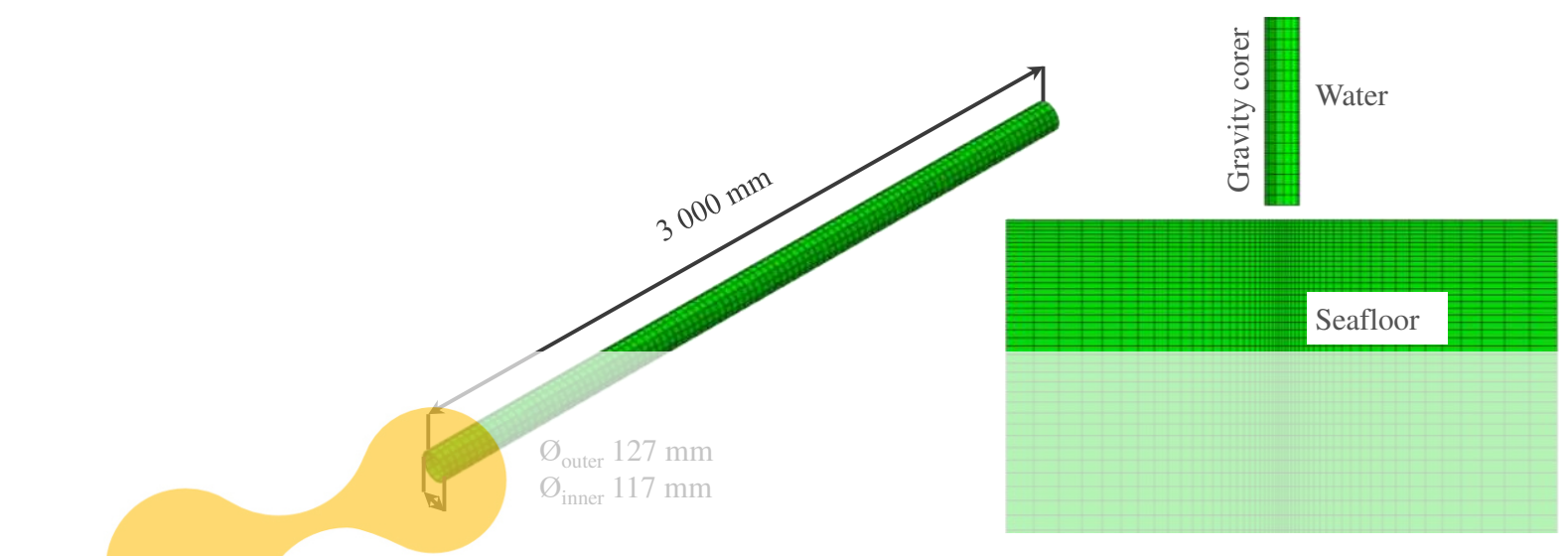

Figure 1: Gravity corer - rigid body with known mechanical properties (left); seafloor sediments - half-space with variable nonlinear rheological properties (right)
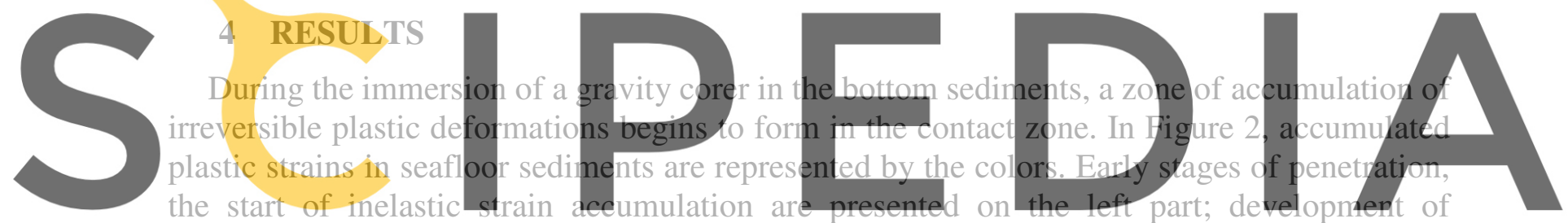
accumulated strain zones is in the middle; and final stage, large displacements of seafloor Register fodfireetatatateps 1 \&vighw.scipedia.com to download the version without the watermark
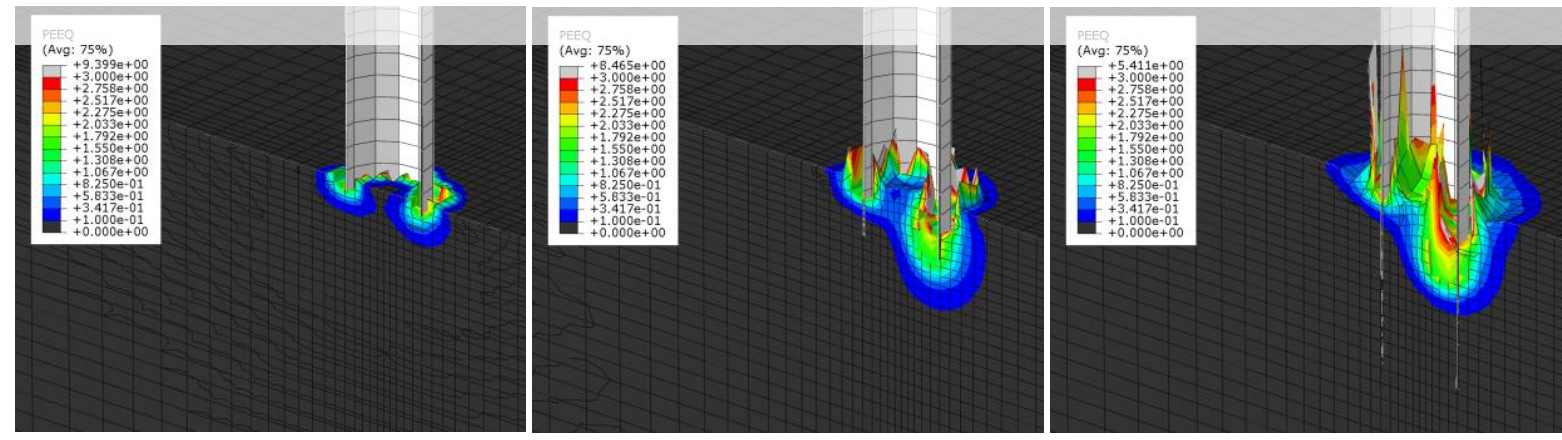

Figure 2: Distribution of accumulated plastic deformations during the immersion of the gravity corer in the bottom sediments

The dynamics of the gravity corer's immersion in the bottom sediments are shown in Figures 3-5. The rheological parameters were varied in the sediment models: density from 1790 to $1940 \mathrm{~kg} / \mathrm{m}^{3}$, Young's modulus from 2.2 to $12.7 \mathrm{MPa}$, cohesion from 8 to $10 \mathrm{kPa}$, and internal 
friction angle from 16.2 to $30^{\circ}$. The Poisson's ratio (0.3) and the dilatancy angle $\left(0^{\circ}\right)$ were constant.

The moment when the gravity corer touches the bottom sediments is taken as the initial point. Figure 3 shows the results of calculations for bottom sediments models with a cohesion of $10 \mathrm{kPa}$ and an internal friction angle of $20^{\circ}$. The values of Young's modulus varied in models 1-7: model 1 - 3.5 MPa, model 2 - $4 \mathrm{MPa}$, model 3 - $3 \mathrm{MPa}$, model $4-4 \mathrm{MPa}$, model 5 $6 \mathrm{MPa}$, model 6- $7 \mathrm{MPa}$ and model $7-10 \mathrm{MPa}$.

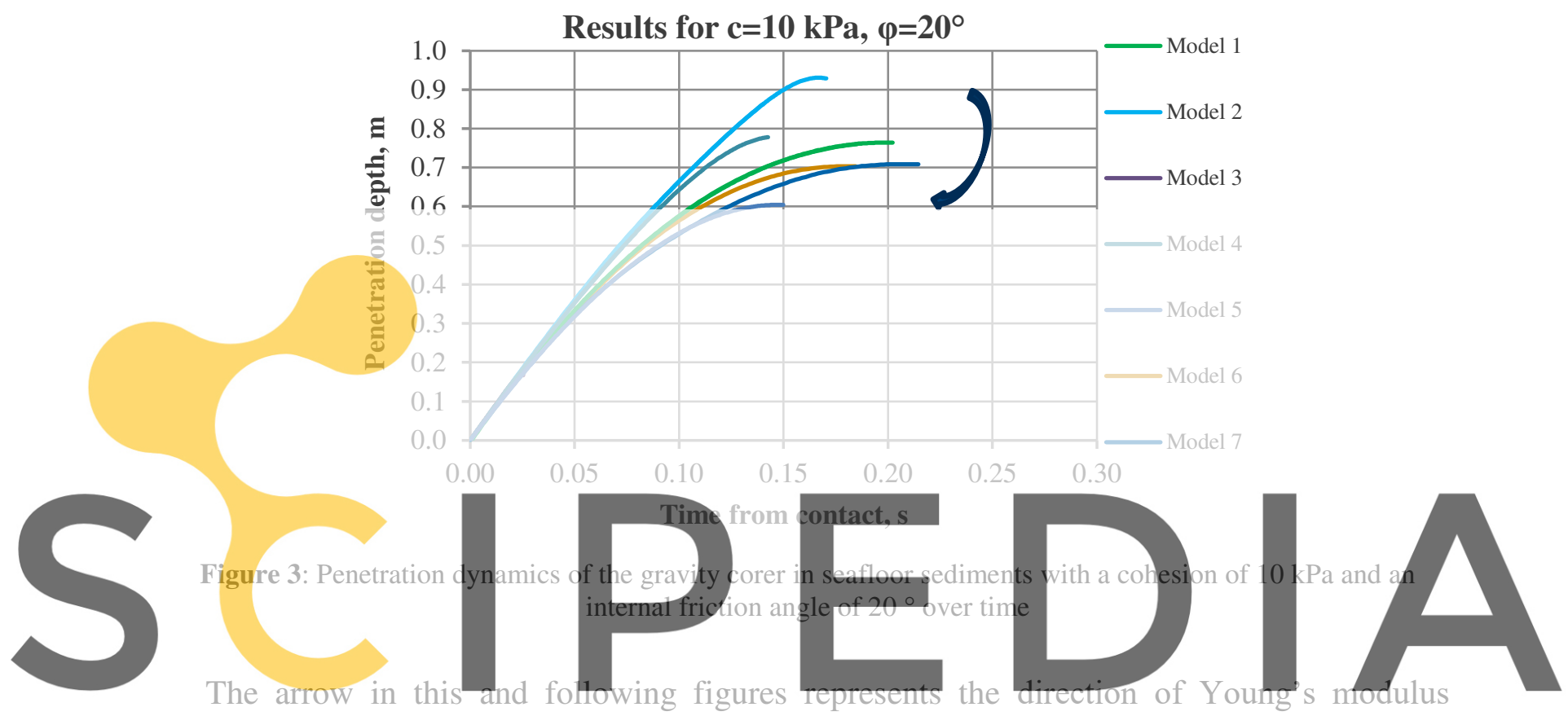

increase: it is natural for the sample to reach lower maximum penetration depth in case of high

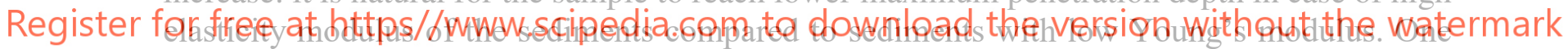

may clearly see from the presented results that the general behavior of the gravity corer is

roughily the same for all models, but, depending on mechanical properties of the sediments, its maximum penetration depth, time elapsed from the contact at the moment of full stop, curvature, and size of the linear section of the analyzed dependency change. Speaking of the inverse problem to be solved, these changes reveal the potential opportunity to solve it.

There are may be several approaches to use the obtained results for the inverse problem solution. From the one hand, one can somehow parametrize the obtained curves and analyze the impact of changes in rheological properties of seafloor sediments on the features of this approximation. This opportunity is provided by the same general behavior of penetration depth vs. time dependencies analyzed here. Nevertheless, there exist risks of limiting the applicability of the obtained results to other model. As it has been mentioned before, numerical experiments discussed in the current paper were only carried out for simplified rheology of seafloor sediments: their possible viscous properties have not been taken into account in this study. So, from now on we will limit the usage of the obtained results in a simpler way: only two parameters, easily extracted from the obtained dependencies will be used for inverse problem analysis. The potential more complicated account is among the main perspectives of the study. 
Figure 4 shows the results of calculations for bottom sediments models with a cohesion of $10 \mathrm{kPa}$ and an internal friction angle of $25^{\circ}$. The values of Young's modulus varied in models 8-16: model 8 - $12 \mathrm{MPa}$, model 9-11 MPa, model 10 - $10 \mathrm{MPa}$, model 11 - $9 \mathrm{MPa}$, model 12 $-8 \mathrm{MPa}$, model $13-7 \mathrm{MPa}$, model $14-6 \mathrm{MPa}$, model $15-5 \mathrm{MPa}$ and model $16-4 \mathrm{MPa}$.

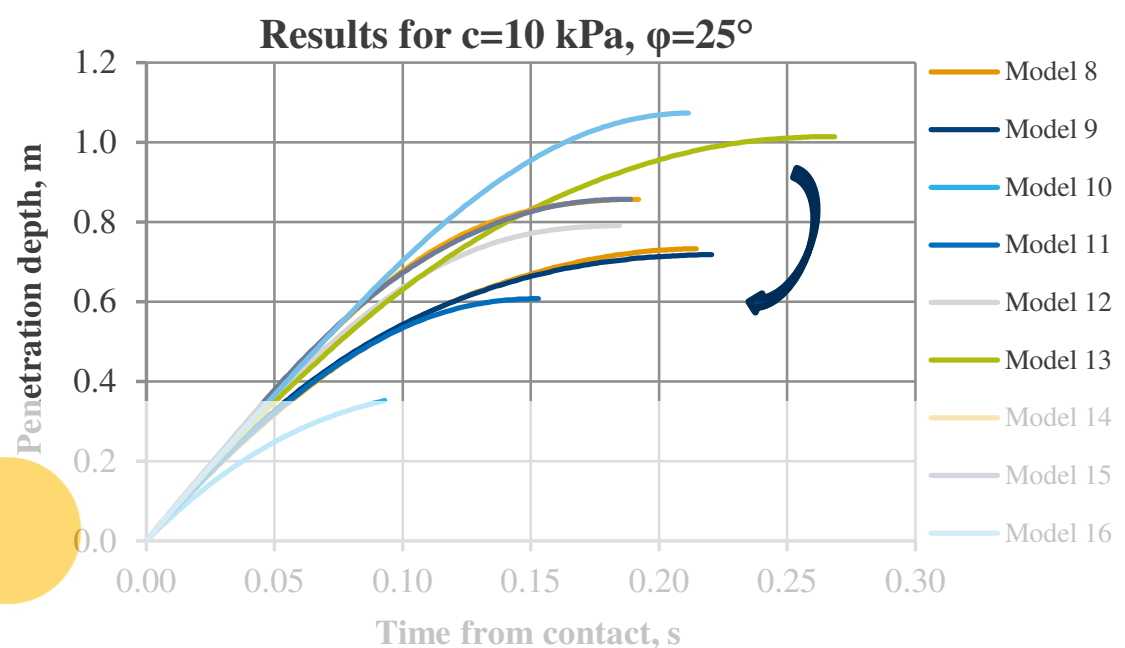

Figure 4: Penetration dynamics of the gravity corer in seafloor sediments with a cohesion of $10 \mathrm{kPa}$ and an
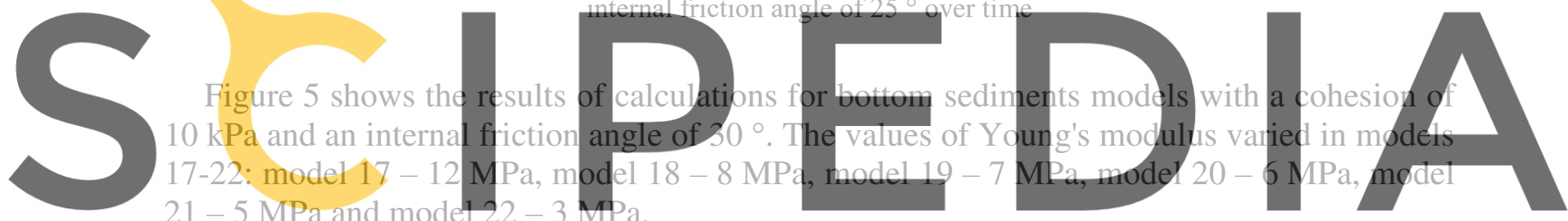

Register for free at https//www.scipedia. com to download the version without the watermark

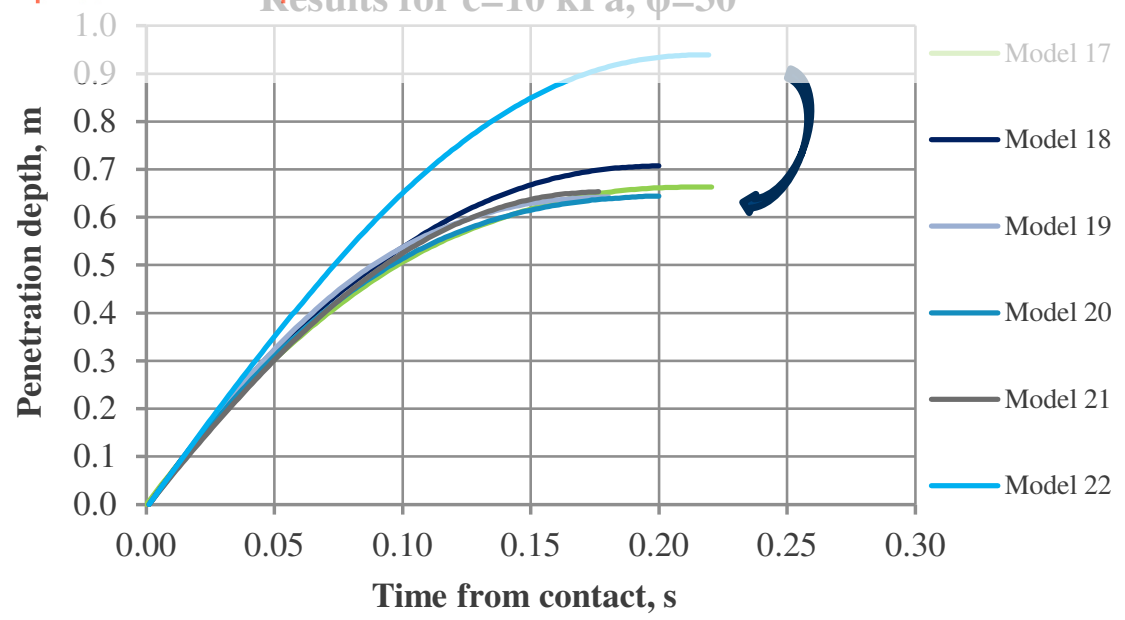

Figure 5: Penetration dynamics of the gravity corer in seafloor sediments with a cohesion of $10 \mathrm{kPa}$ and an internal friction angle of $30^{\circ}$ over time 
The numerical experiments discussed in the paper revealed the relationship between depth of immersion of the sampler and Young's modulus for varied internal friction angle. It was shown that the depth of immersion of the gravity corer decreased with increasing Young's modulus.

Figure 6 shows a possible solution to the inverse problem. The depths of the maximum immersion of the gravity corer in the ground and the time to its complete stop, shown in Fig. 35 , are presented as functions of the upper layers of bottom sediments' mechanical properties from the product of Young's modulus by the sine of the internal friction angle.

It can be easily seen from the obtained results that the relationship between analyzed corer penetration dynamics and rheological properties of seafloor sediments is strongly nonlinear. That means that the inverse problem of seafloor sediments mechanical properties estimation during gravity corer penetration may be solved with different efficiency depending on the properties of the sediments. Weak sediments with low elastic moduli and strength properties make the penetration depth dependency on mechanical properties rather sensitive to small changes in Young's modulus and internal friction (see left part of Fig. 6). At the same time, stronger sediments reveal lesser sensitivity meaning that the difficulty of inverse problem solution rises for stronger sediments. One might expect that there might be many equivalent solutions for that case compared to the case of weak sediments.
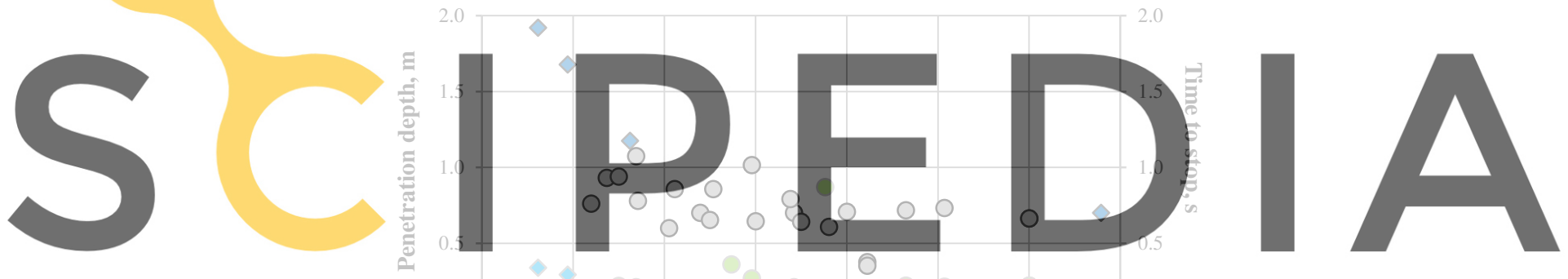

Register for free at https//wyw.scipedia.com to download the version without the watermark

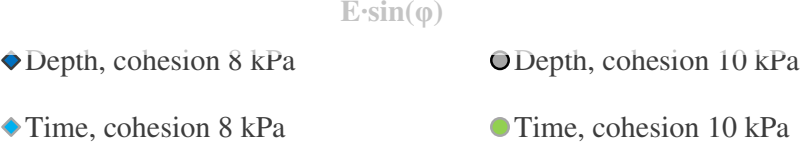

Figure 6: Dependence of the parameters of the dynamics of the immersion of the gravity corer on the mechanical properties of the upper layers of bottom sediments

\section{CONCLUSIONS}

For now, the main drawbacks of the numerical model are the lack of consideration for the mechanical interaction of the tube with the liquid, the lack of consideration for ground creep and a wide range of mechanical properties of bottom soils. Physical modeling can be performed to verify the numerical model using a material with known mechanical properties as a bottom sediment simulation.

The results are the following:

- The depth of immersion of a gravity corer in numerical experiments is varied from 0.6 
to $2 \mathrm{~m}$, which coincides with field experiments' results.

- Same parameters govern dynamics of gravity corer penetration and stability of loadbearing structures;

- Features of penetration dynamics - total depth and time, curvature, and others - are altered during variation of seafloor sediments mechanical properties.

The obtained results make it possible to improve the quality of model of mechanical properties of the seafloor sediments via providing an alternate source of information related to mechanical properties of the first meters of depth of seafloor sediments. This improvement provides the corresponding increase in mechanical modeling of infrastructure stability and decreases the risks accompanying offshore field development.

\section{FUNDING}

This work was supported by Russian Science Foundation project № 19-77-10062.

\section{REFERENCES}

[1] Marchenko, I.A. Engineering surveys for location of drilling platforms in the Arctic seas. Scientific and technical collection News of gas science (2019) 2(39):149-156.

[2] Randolph, M., Cassidy, M., Gourvenec, S., \& Erbrich, C. Challenges of offshore geotechnical engineering. Proceedings of the international conference on soil mechanics and geotechnical engineering (2005) 16(1):123.

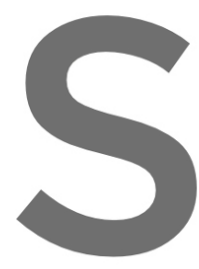

[3] Tikhotskiy, S., Dubinya
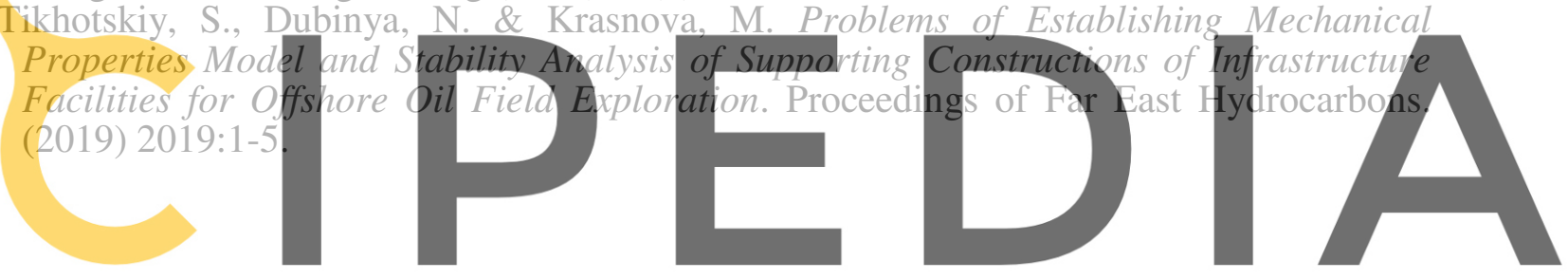

Register for free at https//www.scipedia.com to download the version without the watermark 